\title{
Innovationen für ein gesundes, natürlich schönes Lächeln
}

Philips, Hersteller der Sonicare Schallzahnbürsten, wird mit zahlreichen Innovationen für ein gesundes, natürlich schönes Lächeln auf der IDS vertreten sein. Eines der Zahnpflege-Highlights ist die weiterentwickelte Lösung zur Zahnzwischenraumreinigung: Philips Sonicare AirFloss Ultra. Das Produkt entfernt Plaque-Biofilm noch effektiver und verringert so Zahnfleischbluten.

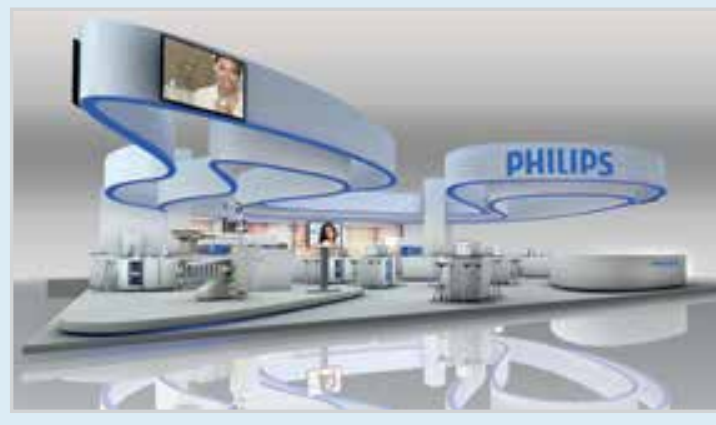

Eine Studie zeigt, dass sich die Anzahl der Blutungsstellen bei Anwendern um 73\% reduziert (in der Praxis durchgeführte Studie mit 340 US-Dentalhygienikerinnen, in der 670 Patienten mit leichter bis mittelschwerer Gingivitis instruiert wurden, Philips Sonicare AirFloss mit Mundspülung über einen Zeitraum von 60 Tagen zu benutzen). Ein Besuch am Philips Messestand lohnt sich: An den ZahnputzTeststationen haben Besucher die Möglichkeit, den AirFloss Ultra und die neuen Sonicare Schallzahnbürsten selbst zu testen. Abgerundet wird das Angebot durch live Zahnaufhellungs-Behandlungen mit Philips ZOOM sowie attraktive Messeangebote.

Tipp: Besucher können sich vor der IDS als Philips VIPs registrieren und ersparen sich so lange Wartezeiten am Messestand und an den Zahnputz-Teststationen. Zahnarztpraxen können sich einfach unter philips. ids@philips.com für den E-Mail-Newsletter anmelden und sich den VIP-Pass sichern.

Halle 11.3, Stand G010

Nach einer Pressemitteilung der

Philips GmbH, Hamburg

Internet: www.philips.de/sonicare, www.philips

de/zoom 